\title{
Perceived Readiness to Practice among BSC Honors in Nursing Graduates: Implications for Training
}

\author{
Clara Haruzivishe*, Doreen Mukona Macherera \\ College of Health Sciences, University of Zimbabwe, Harare, Zimbabwe \\ Email: *claraopha@gmail.com
}

How to cite this paper: Haruzivishe, C. and Macherera, D.M. (2021) Perceived Readiness to Practice among BSC Honors in Nursing Graduates: Implications for Training. Open Access Library Journal, 8: e7138.

https://doi.org/10.4236/oalib.1107138

Received: January 7, 2021

Accepted: March 30, 2021

Published: April 2, 2021

Copyright $\odot 2021$ by author(s) and Open Access Library Inc.

This work is licensed under the Creative Commons Attribution International License (CC BY 4.0).

http://creativecommons.org/licenses/by/4.0/

\begin{abstract}
New nurses, at all levels of qualification, are generally perceived as not meeting expectations for safe nursing practice. Unfortunately, they are expected to be job ready, demonstrate competence in the provision of evidence-based care, practise independently, and assume accountability and responsibility for their own actions by hospital managers and nursing authorities. This was a cross-sectional analytic survey conducted online with a random sample of $118 \mathrm{BScN}$ graduates from the University of Zimbabwe, Department of Nursing Science. Contact numbers, email addresses and social media platforms were used to contact the graduates. An adapted version of the Casey Fink Readiness for Practice Questionnaire (CFRPQ) questionnaire was used to collect data. It had 3 sections namely; Section A-Demographic data, Section B-Adapted Readiness to Practice Questionnaire and Section C-Needs to enhance readiness to practice questionnaire. The questionnaire was uploaded online with a link that was sent to participants who had given consent. They were filled in and returned to the researcher. Constant reminders in the form of emails, and text messages were sent out to enhance response. Approvals for the study were granted by the Joint Research and Ethics Committee and the Medical Research Council of Zimbabwe. The study was conducted according to the requirements of the Declaration of Helsinki. All participants gave informed consent. The researchers had sole access to fill in surveys which were kept in a password protected electronic folder. Data were collected over 6 weeks from the $28^{\text {th }}$ of July to the $11^{\text {th }}$ of September 2020. It was coded and analysed using STATA version 15. Descriptive statistics were used to analyse demographic data and readiness to practice scores. Qualitative data on needs to enhance readiness to practice were also coded and analysed thematically. Response rate was 53\%. Majority of participants (at least 86.4\%) expressed confidence caring for patients on medical surgical units. Many participants
\end{abstract}


highlighted the need for more supervised clinical placements to enhance readiness to practice.

\section{Subject Areas}

Gynecology \& Obstetrics

\section{Keywords}

Readiness to Practice, New Graduates, Nursing Degree Programmes, Job Satisfaction, Clinical Practice

\section{Introduction}

Readiness to practice is "having a generalist foundation and some job specific capabilities, providing safe client care, keeping up with the current realities of nursing practice, being well equipped with the tools needed to adapt to the future needs of clients, and possessing a balance of doing, knowing and thinking" [1]. It also refers to being competent and having the knowledge, skills and judgment that is required for such role performance [2]. New nurses, at all levels of qualification, are generally perceived as not meeting expectations for safe nursing practice [3]. Unfortunately, they are expected to be job ready, demonstrate competence in the provision of evidence-based care, practise independently, and assume accountability and responsibility for their own actions by hospital managers and nursing authorities [1]. Graduates are required to apply their learning from the academic setting into the clinical environment immediately upon entry into practice [4]. It remains partly upon nurse educators to identify student learning and professional development needs as students progress toward practice [3]. This is because preparation of nursing students for their role as future registered nurses is an essential and complex endeavor and is a shared responsibility between academic and clinical health care organizations [5].

Clinical placements have been reported to increase readiness to practice among new graduates. Caring for multiple patients involves a high level of complexity, requires confidence and this can be achieved with sufficient [6] [7]. The clinical competence and fitness for practice upon completion of undergraduate education have been questioned over the past decade [8]. According to Blegen et al., university degree programmes offer better nursing care when compared to nurses trained from non-university nursing programmes [9]. Because nurses with university degrees reason better, think critically and make sound clinical judgements when executing patient care [10] patients nursed by nurses with university degrees have better health outcomes when compared to patients nursed by nurses with other qualifications [11] [12]. This is because university-based nursing degree programmes are quality assured by university-wide quality assurance processes and professional regulatory councils [13] so they meet both educational and professional nursing standards. This is not common 
practice in non-university-based nursing programmes. University-based degree programmes, in addition to the generic nursing sciences, integrate basic and social sciences quintessential to the reasoning processes inherent in nursing care [14] and are facilitated by experts. Lecturers in these university-based nursing degree programmes have advanced educational and professional qualifications at a level higher than the qualification they are facilitating. The undergraduate nursing students are taught both in the university, and university accredited clinical practice sites.

University-based nursing degree programmes are not without controversies. Issues raised against these degrees include having content but without clinical practice [15] [16], failure to "hit the ground running" and requiring extensive induction processes [17]. Some graduates have also complained of the limited clinical exposure, limited clinical accompaniment during training and the lack of structured practical components in their degree programmes [18]. There is need for more robust evaluation of university-based nursing degree programmes especially in resource-limited settings in Africa.

The University of Zimbabwe is the oldest university and was the first to provide medical education in Zimbabwe. Nursing Bachelor's degree program was established in 1985. To date the department has developed tremendously offering a variety of programs from Bachelor of Science, Honors Degree in Nursing (BSc N) to DPhil Level. The programs currently offered by the Department of Nursing Science are; Bachelor of Science honors degree in Nursing Science (4year full time), Master of Science degree in Nursing Science (3 years Part Time and 18 months' full time) and Doctor of Philosophy in Nursing. $\mathrm{MCH}$ at undergraduate level is offered in the $3^{\text {rd }}$ and $4^{\text {th }}$ years of study.

The Department of Nursing Science continues to be a model for other universities in the country that have established nursing departments. The department has also worked in collaboration with other universities through exchange programs and consortia for staff development and capacity building. The NORHED grant, run by the Department of Nursing Science in collaboration with the University of Zambia, Department of Nursing Science, Kamuzu College of Nursing, Malawi and University of Oslo, Norway, specifically aimed to improve $\mathrm{MCH}$ education and practice by offering training in $\mathrm{MCH}$ at both undergraduate and postgraduate (MSc Nursing and Doctor of Philosophy in Nursing). We proposed that quality of clinical learning for BSc Nursing students, can be improved by understanding the perceptions of nurses of readiness to practice which is very important to clinical practice. There has been little to no research assessing whether or not BSc Nursing graduates are prepared to practice in various units in health care institutions. The purpose of this study, therefore, was to assess the readiness to practice among $\mathrm{BScN}$ graduates.

\section{Methods}

The study utilised a cross-sectional analytic survey design and it was conducted 
online. Participants were a random sample of $\mathrm{BScN}$ graduates from the University of Zimbabwe, Department of Nursing Science who graduated from 2002-2019. Out of the 223 surveys sent online, only 118 were responded to, translating to a $53 \%$ response rate. Calculation of sample size for a finite population was done assuming a total population $(\mathrm{N})$ of $540,95 \%$ confidence interval, $\alpha$ of 0.05 and $Z$ of 1.96. Contact numbers, email addresses and social media platforms were used to contact the graduates. Data were collected through online surveys using an adapted version of the Casey Fink Readiness for Practice Questionnaire (CFRPQ) questionnaire. It had 3 sections namely; Section A-Demographic data, Section B-Adapted Readiness to Practice Questionnaire Medical-Surgical Nursing Maternal Child Health/Midwifery Mental Health/ Psychiatric Nursing Community Health Nursing and Section C-Needs to enhance readiness to practice questionnaire. The CFRPQ is a tool developed to assess readiness to practice in nursing. It elicits readiness for clinical problem solving, learning techniques, professional identity and trials and tribulations of the nursing career. Responses are graded on a Likert scale. The questionnaire was uploaded online with a link that was sent to participants who had given consent. They were filled in and returned to the researcher. Constant reminders in the form of emails, and text messages were sent out to enhance response. Approvals for the study were granted by the Joint Research and Ethics Committee and the Medical Research Council of Zimbabwe. The study was conducted according to the requirements of the Declaration of Helsinki. All participants gave informed consent. The researchers had sole access to fill in surveys which were kept in a password protected electronic folder. Data were collected over 6 weeks from the $28^{\text {th }}$ of July to the $11^{\text {th }}$ of September 2020. It was coded and analysed using STATA version 15. Descriptive statistics were used to analyse demographic data and readiness to practice scores. Qualitative data on needs to enhance readiness to practice were also coded and analysed thematically.

\section{Results}

This section presents results of the survey. The response rate was 53\% (118 responses were received out of the 223 questionnaires distributed). Mean age of the participants was 31 years while mean years since qualification was 7 . Table 1 presents demographic data.

\subsection{Readiness to Practice}

Table 2 presents results of readiness to practice in Medical-surgical Nursing.

\subsection{Satisfaction with Career, Instructor Feedback, Simulations and Interactions with Interdisciplinary Teams}

Table 3 presents responses to satisfaction with career, instructor feedback, simulations and interactions with interdisciplinary teams. These were responses to the section of the CFRPQ on satisfaction of new graduates with nursing as a 
Table 1. Participant and demographic characteristics $(n=118)$.

\begin{tabular}{|c|c|c|}
\hline Variable & Frequency & Percentage (\%) \\
\hline \multicolumn{3}{|l|}{ Mean age of participants. 31 years } \\
\hline \multicolumn{3}{|l|}{ Mean years since qualification: 7 years } \\
\hline \multicolumn{3}{|l|}{ Gender } \\
\hline Female & 62 & 52.5 \\
\hline Male & 56 & 47.5 \\
\hline \multicolumn{3}{|l|}{ Place of practice } \\
\hline Government & 55 & 46.6 \\
\hline NGO & 16 & 13.6 \\
\hline Private institution & 33 & 28.0 \\
\hline University & 3 & 2.5 \\
\hline N/A & 11 & 9.3 \\
\hline \multicolumn{3}{|l|}{ Area of practice } \\
\hline Acute care & 4 & 3.4 \\
\hline Community & 11 & 9.3 \\
\hline Education & 4 & 3.4 \\
\hline $\mathrm{MCH}$ & 7 & 5.9 \\
\hline Med-surg & 65 & 55.1 \\
\hline Mental health & 3 & 2.5 \\
\hline Public health & 5 & 4.2 \\
\hline Other & 6 & 5.1 \\
\hline N/A & 13 & 11.0 \\
\hline \multicolumn{3}{|l|}{ Country of practice } \\
\hline Zimbabwe & 82 & 69.5 \\
\hline African Country & 14 & 0.8 \\
\hline Australia & 5 & 4.2 \\
\hline Middle East & 3 & 2.5 \\
\hline United Kingdom/Ireland & 7 & 5.9 \\
\hline N/A & 7 & 5.9 \\
\hline \multicolumn{3}{|l|}{ Employment status: } \\
\hline \multicolumn{3}{|c|}{ Are you currently working in a healthcare related position } \\
\hline Yes & 88 & 74.6 \\
\hline No & 30 & 25.4 \\
\hline
\end{tabular}

career, satisfaction with feedback from instructors regarding their performance in the clinical area, use of simulation to enhance understanding of concepts and confidence in interacting with interdisciplinary teams in patient care.

\subsection{Training Needs}

This section was qualitatively done. The 2 themes that emerged were trained needs and strategies to enhance readiness to practice. Table 4 below presents the 
Table 2. Perceived readiness to practice-medical-surgical nursing $(\mathrm{n}=118)$.

\begin{tabular}{|c|c|}
\hline Statement & $\begin{array}{l}\text { Response } \\
\text { (agree) }^{\dagger}\end{array}$ \\
\hline $\begin{array}{l}\text { I have confidence in managing a patient care assignment on an adult } \\
\text { medical-surgical unit: Caring for } 2 \text { patients. }\end{array}$ & $107(90.7 \%)$ \\
\hline $\begin{array}{l}\text { I have confidence in managing a patient care assignment on an adult } \\
\text { medical-surgical unit: Caring for } 3 \text { patients. }\end{array}$ & $109(92.4 \%)$ \\
\hline $\begin{array}{l}\text { I have confidence in managing a patient care assignment on an adult } \\
\text { medical-surgical unit: Caring for } 4 \text { patients. }\end{array}$ & $102(86.4 \%)$ \\
\hline I feel confident communicating with other professionals e.g. physicians. & $105(89 \%)$ \\
\hline $\begin{array}{l}\text { I am comfortable communicating with adult medical-surgical } \\
\text { patients from diverse populations. }\end{array}$ & $105(89 \%)$ \\
\hline $\begin{array}{l}\text { I am comfortable delegating tasks to the nursing assistant in adult } \\
\text { medical-surgical. }\end{array}$ & $101(85.6 \%)$ \\
\hline $\begin{array}{l}\text { I have difficulty documenting adult medical-surgical care in the } \\
\text { electronic medical record. }\end{array}$ & $11(9.3 \%)$ \\
\hline I have difficulty prioritizing patient care needs. & $7(5.9 \%)$ \\
\hline $\begin{array}{l}\text { My clinical instructor provided feedback about my readiness to assume an } \\
\text { RN role in adult medical-surgical care. }\end{array}$ & $76(64.4 \%)$ \\
\hline I am confident in my ability to problem solve. & $111(94.1 \%)$ \\
\hline I feel overwhelmed by ethical issues in my patient care responsibilities. & $27(22.9 \%)$ \\
\hline I have difficulty recognizing a significant change in my patient's condition. & $4(3.4 \%)$ \\
\hline $\begin{array}{l}\text { I have had opportunities to practice skills and procedures more } \\
\text { than once. I am comfortable asking for help. }\end{array}$ & $114(96.6 \%)$ \\
\hline I use current evidence to make clinical decisions. & $103(87.3 \%)$ \\
\hline $\begin{array}{l}\text { I am comfortable communicating and coordinating care with } \\
\text { interdisciplinary team members. }\end{array}$ & $113(95.8 \%)$ \\
\hline Simulations have helped me feel prepared for clinical practice. & $98(83.1 \%)$ \\
\hline $\begin{array}{l}\text { Writing reflective journals/logs provided insights into my own } \\
\text { clinical decision-making skills. }\end{array}$ & $58(49.2 \%)$ \\
\hline I feel comfortable knowing what to do for a dying patient. & $79(66.9 \%)$ \\
\hline I am comfortable taking action to solve problems. & $111(94.9 \%)$ \\
\hline I feel confident identifying actual or potential safety risks to my patients. & $112(94.9 \%)$ \\
\hline $\begin{array}{l}\text { I am satisfied with choosing nursing as a career. I feel ready } \\
\text { for the professional nursing role. }\end{array}$ & $90(76.3 \%)$ \\
\hline
\end{tabular}

'Indicates number of respondents who agree with the statements posed (i.e. who provided a rating of 4 or 5 on the Likert scale, indicating agree or strongly agree).

Table 3. Satisfaction with career, instructor feedback, simulations and interactions with interdisciplinary teams $(\mathrm{n}=118)$.

\begin{tabular}{lc}
\hline \multicolumn{1}{c}{ Statement: } & Response (agree) ${ }^{1}$ \\
\hline $\begin{array}{l}\text { I am satisfied with choosing nursing as a career. I feel ready } \\
\text { for the professional nursing role. }\end{array}$ & $90(76.3 \%)$ \\
$\begin{array}{l}\text { My clinical instructor provided feedback about my } \\
\text { readiness to assume an RN role in }\end{array}$ & $76(64.4 \%)$ \\
$\begin{array}{l}\text { Simulations have helped me feel prepared for clinical practice. } \\
\text { I am comfortable communicating and coordinating care } \\
\text { with interdisciplinary team members }\end{array}$ & $98(83.1 \%)$ \\
\hline
\end{tabular}

${ }^{1}$ Median and range of responses on a 5 point Likert scale, from $1=$ strongly disagree to $5=$ strongly agree. 
Table 4. Themes identified from qualitative data $(n=118)$.

\begin{tabular}{|c|c|c|}
\hline Theme & Codes & Verbatim quotes \\
\hline $\begin{array}{l}\text { Training } \\
\text { needs }\end{array}$ & $\begin{array}{l}\text { Perioperative care } \\
\text { Cardio pulmonary } \\
\text { resuscitation } \\
\text { Suturing } \\
\text { Peritoneal dialysis } \\
\text { Interpretation of } \\
\text { laboratory results }\end{array}$ & $\begin{array}{l}\text { 1) There are some procedures I am not comfortable } \\
\text { with such as caring for a patient undergoing surgery } \\
\text { 2) We need more practice with invasive procedures } \\
\text { such as peritoneal dialysis } \\
\text { 3) I am not comfortable suturing big wounds } \\
\text { 4) I need to master interpretation of lab results }\end{array}$ \\
\hline $\begin{array}{l}\text { Strategies to } \\
\text { enhance } \\
\text { readiness to } \\
\text { practice }\end{array}$ & $\begin{array}{l}\text { Introducing more } \\
\text { clinical practice } \\
\text { Allow students to } \\
\text { specialise in the } \\
\text { final year } \\
\text { Have more simulations } \\
\text { Extend support to } \\
\text { graduates } \\
\text { Avail more counselling } \\
\text { and career guidance }\end{array}$ & $\begin{array}{l}\text { 1) There should be more time in clinical practice. } \\
\text { Assisting students in carrying out procedures in } \\
\text { clinical area. Close supervision of students in } \\
\text { practice and making sure the students have } \\
\text { managed to carry out most if not all } \\
\text { procedures in the clinical area. } \\
\text { 2) The four-year program period post A level is } \\
\text { enough to allow BScN graduates to come out with } \\
\text { clearly documented specialisations in Midwifery, } \\
\text { Critical Care, Community health, Anesthesiology, } \\
\text { Oncology according to preferences. } \\
\text { 3) A support system for graduates } \\
\text { Compulsory rotation of specialty areas for } \\
\text { new graduates e.g. every } 4 \text { - } 6 \text { months } \\
\text { 4) Make counselling \& more carrier guidance } \\
\text { services readily available }\end{array}$ \\
\hline
\end{tabular}

themes and the codes as they were identified.

\section{Discussion}

\subsection{Demographics}

This is the first study to assess readiness to practice among baccalaureate nursing students in Zimbabwe. Mean age of the participants was 31 years. There were almost equal proportions of males and females $(47.5 \%$ and $52.5 \%$ respectively). Majority (46.6\%) working in government institutions while majority (55.1\%) also worked in medical-surgical units. This is because the programme is an honors degree in which they major in medical-surgical nursing. Majority still worked in Zimbabwe (69.5\%) at the time of the survey and majority worked in healthcare related positions (74.6\%).

\subsection{Readiness to Practice}

Readiness to practice was measured using an adapted version of the Casey Fink Readiness to Practice Questionnaire. At least 90\% felt confident taking care of increasing number of patients, communicating with the health care team and performing various selected procedures. Similar levels of readiness have been reported elsewhere [19]. This is because the degree programme is made up of a number of varied placements in medical surgical units and other units. However, other studies have reported inadequacies in "leadership and management skills, electronic health record management, delegation skills, the ability to 
manage multiple patient care assignments, or recognize changes in patient condition" [2]. Studies conducted in Australia reported lack of confidence in caring for increasing number of patients among newly graduated nurses [19] [20]. The higher levels of readiness to practice reported in our study could be due to the fact that clinical learning in our country resembles real practice as students learn on actual patients in real world settings [21]. Increased readiness has also been associated with younger age [22] [23], prior or current healthcare experience, and greater professional competence [23].

Clinical education which is one of the most important parts of nursing education is very important for personal development and promotion of manual dexterity practical skills [24]. Nursing education is such that nursing students always play the dual role of direct education and participation in patient caring [25]. Other students have reported that they felt that they were "a pair of hands" in the clinical setting [26]. Baccalaureate students are generally associated with more desirable patient outcomes [9] and have generally reported high levels of readiness to practice [27] [28]. One study reported lower congestive heart failure mortality, decubitus ulcers, failure to rescue, and postoperative deep vein thrombosis or pulmonary embolism and shorter length of stay in hospitals with a higher percentage of RNs with baccalaureate or higher degrees had [9]. According to Wolff et al., four aspects of readiness for practice include; having a generalist foundation and some job-specific capabilities, providing safe client care, keeping up with current realities and future possibilities, and possessing a balance of doing, knowing and thinking [1]. A university-based clinical school of nursing has "the potential to offer a model for enhancing new graduate nurses' preparedness for practice" [29]. However, no matter how ready these new nurses are at transition, clinical supervision remains key in their training. Clinical supervision, when a professional expert provides support, guidance and feedback to nursing students or novice nurses to develop skills of nursing practice, is an important element in facilitating learning in the clinical setting [30].

However, barely half (49.2\%) participants expressed confidence in writing reflective journals/logs to provide insights into one's clinical decision-making skills. One study conducted in the United States also reported similar results [28]. Similar to our study, students in that study also reported less confidence in simulation care of dying patients [27] [28]. Reflective journaling is used in clinical education to judge students' clinical thinking; however, studies indicate that students may benefit from guided reflections [31]. It also promotes development of cultural humility in students [32]. It is very important to promote reflective journaling as a tool for developing critical thinking skills which are very vital to nursing [33].

More than a fifth (22.9\%) reported being overwhelmed by ethical issues in patient care responsibilities. Although there is a module addressing ethical issues in practice in the $\mathrm{BScN}$ programme, it is very important to reemphasise importance of ethical practice to graduating classes. Professional ethics, despite the 
obvious importance, has not been studied much in nursing science. It is prudent to impart more knowledge of professional ethics to understand and support moral decision-making. This will also help to respond to the challenges of current changes in health care and society [34].

\subsection{Needs to Enhance Readiness to Practice}

This section was done qualitatively. Training needs identified were specific clinical procedures, namely; perioperative care, cardio pulmonary resuscitation, suturing, peritoneal dialysis and interpretation of laboratory results. Similar gaps in training have also been reported in literature [2] [19] [20]. Studies conducted in developed countries have yielded similar results. New graduates reported being uncomfortable "performing invasive procedures and reported low levels of confidence in the area of professional identity" [6]. This can result from ever increasing demands on the health care system, the diverse nature of nursing practice resulting in difficulties creating standard of practice, complex nature of evaluating cognitive, affective, and psychomotor skills, and gaps between nursing education and clinical practice [1] [35]. Students are evaluated course by course rather than by their ongoing progression and there are huge numbers of students resulting in lack of clinical opportunities and poor supervision [36] [37]. Other reasons include, subjectivity of student evaluations, lack of clear definition of the terms related to practice readiness and evaluation, lack of reliability and validity of evaluation tools and limited resources [1] [35] [37]. One study conducted in Swaziland also reported that students lacked support from training institutions upon employment [38].

Possible solutions were also suggested and these were introduction of more clinical practice, allowing students to specialise in the final year, having more simulations, extending support to graduates and availing more counselling and career guidance. These solutions have been cited in other studies [6] [30]. Specialization in a specific niche makes one become an expert in their field and influence practice, education and healthcare outcomes. Pursuing a specialization also assists in shaping the future of the health care industry [39]. However, the decision to specialize and advance professionally is a commitment that generally requires a Master's degree in nursing. Quite agreeably, the benefits are far-reaching, hence, continuing education a worthy pursuit [39]. Clinical practice remains the mainstay of nursing preparation for practice [21]. Of note from this study, is the need for students to specialize in their final year.

\section{Conclusion}

Majority of graduates expressed high levels of readiness to practice despite having challenges with selected nursing procedure. Based on these findings, modules on Medical-surgical, Community Health, Mental Health/Psychiatric and Maternal Child Health addressing gaps highlighted in the study were developed by various content specialists. They were made available online for the current 
graduating classes to take. This, hopefully, enhanced their readiness to practice.

\section{Limitations}

This was a cross-sectional survey design conducted online. Response rate was very low (53\%) probably owing to high cost of internet services. A response rate of at least $70 \%$ would be satisfactory for online surveys.

\section{Conflicts of Interest}

The authors of this paper are lecturers in the department from which the participants graduated from. However, this did not have any bearing on the outcome of the study.

\section{References}

[1] Wolff, A.C., Regan, S., Pesut, B. and Black, J. (2010) Ready for What? An Exploration of the Meaning of New Graduate Nurses' Readiness for Practice. International Journal of Nursing Education Scholarship, 7, Article No. 7. https://doi.org/10.2202/1548-923X.1827

[2] Casey, K., Fink, R., Jaynes, C., Campbell, L., Cook, P. and Wilson, V. (2011) Readiness for Practice: The Senior Practicum Experience. Journal of Nursing Education, 50, 646-652. https://doi.org/10.3928/01484834-20110817-03

[3] Rusch, L., Manz, J., Hercinger, M., Oertwich, A. and McCafferty, K. (2019) Nurse Preceptor Perceptions of Nursing Student Progress toward Readiness for Practice. Nurse Educator, 44, 34-37. https://doi.org/10.1097/NNE.0000000000000546

[4] Meechan, R., Jones, H. and Valler-Jones, T. (2011) Students' Perspectives on Their Skills Acquisition and Confidence. British Journal of Nursing, 20, 445-450. https://doi.org/10.12968/bjon.2011.20.7.445

[5] Leufer, T. and Cleary-Holdforth, J. (2020) Senior Nursing Students' Perceptions of Their Readiness for Practice Prior to Final Year Internship: Part 2-A Qualitative Perspective. Dimensions of Critical Care Nursing, 39, 81-90. https://doi.org/10.1097/DCC.0000000000000407

[6] Woods, C., West, C., Mills, J., Park, T., Southern, J., Usher, K., et al. (2015) Undergraduate Student Nurses' Self-Reported Preparedness for Practice. Collegian, 22, 359-368. https://doi.org/10.1016/j.colegn.2014.05.003

[7] Järvinen, T., Eklöf, N. and Salminen, L. (2018) Factors Related to Nursing Students' Readiness to Enter Working Life-A Scoping Literature Review. Nurse Education in Practice, 29, 191-199. https://doi.org/10.1016/j.nepr.2018.01.010

[8] Missen, K., McKenna, L. and Beauchamp, A. (2016) Registered Nurses' Perceptions of New Nursing Graduates' Clinical Competence: A Systematic Integrative Review. Nursing \& Health Sciences, 18, 143-153. https://doi.org/10.1111/nhs.12249

[9] Blegen, M.A., Goode, C.J., Park, S.H., Vaughn, T. and Spetz, J. (2013) Baccalaureate Education in Nursing and Patient Outcomes. The Journal of Nursing Administration, 43, 89-94. https://doi.org/10.1097/NNA.0b013e31827f2028

[10] DeBack, V. and Mentkowski, M. (1986) Does the Baccalaureate Make a Difference? Differentiating Nurse Performance by Education and Experience. Journal of Nursing Education, 25, 275-285.

[11] Aiken, L.H., Sloane, D.M., Bruyneel, L., Van den Heede, K., Griffiths, P., Busse, R., et al. (2014) Nurse Staffing and Education and Hospital Mortality in Nine European 
Countries: A Retrospective Observational Study. The Lancet, 383, 1824-1830. https://doi.org/10.1016/S0140-6736(13)62631-8

[12] Aiken, L.H., Sloane, D.M., Bruyneel, L., Van den Heede, K. and Sermeus, W. (2013) Nurses' Reports of Working Conditions and Hospital Quality of Care in 12 Countries in Europe. International Journal of Nursing Studies, 50, 143-153. https://doi.org/10.1016/j.ijnurstu.2012.11.009

[13] International Confederation of Midwives (2013) ICM Global Standards for Midwifery Education 2010; Amended 2013.

https://www.internationalmidwives.org/assets/files/general-files/2018/04/companio n-guidelines-for-ed-standards-2011---amended-web-edition-june-2013.pdf

[14] Lin, C.-C., Han, C.-Y., Pan, I.-J. and Chen, L.-C. (2015) The Teaching-Learning Approach and Critical Thinking Development: a qualitative Exploration of Taiwanese Nursing Students. Journal of Professional Nursing, 31, 149-157. https://doi.org/10.1016/j.profnurs.2014.07.001

[15] Mekgoe, T.S., Lepedi, K., Makhutle, P.T., Makhado, L., Madiba, K. and Langa, N.S.N. (2019) Experience of Nursing Students Regarding Clinical Support in the Management of TB and HIV Patients in a Primary Healthcare Setting: A Phenomenological Study. The Pan African Medical Journal, 33, Article No. 209. https://doi.org/10.11604/pamj.2019.33.209.15819

[16] Xu, J., Francis, L., Dine, J. and Thomas, T.H. (2018) Unique Experiences of Direct entry BSN/BS-PhD Nursing Students: A Delphi Study. Nurse Education Today, 69, 30-34. https://doi.org/10.1016/j.nedt.2018.06.024

[17] Makua, M.G. (2016) Induction and Professional Development Support of Newly Qualified Professional Nurses during Community Service. University of South Africa, Pretoria.

[18] Donough, G. and Van Der Heever, M. (2018) Undergraduate Nursing Students' Experience of Clinical Supervision. Curationis, 41, Article No. a1833. https://doi.org/10.4102/curationis.v41i1.1833

[19] Güner, P. (2015) Preparedness of Final-Year Turkish Nursing Students for Work as a Professional Nurse. Journal of Clinical Nursing, 24, 844-854.

[20] Usher, K., Mills, J., West, C., Park, T. and Woods, C. (2015) Preregistration Student Nurses' Self-Reported Preparedness for Practice before and after the Introduction of a Capstone Subject. Journal of Clinical Nursing, 24, 3245-3254. https://doi.org/10.1111/jocn.12673

[21] AlMekkawi, M. and El Khalil, R. (2020) New Graduate Nurses' Readiness to Practise: A Narrative Literature Review. Health Professions Education, 6, 304-316. https://doi.org/10.1111/jocn.12996

[22] Pillai, A. (2014) Ready, Set, Practice: A Study of Generational Differences and Their Impact on Senior Baccalaureate Nursing Student Perceived Readiness to Practice. Doctoral Dissertations, ProQuest LLC, Alabama. Retrieved from ProQuest Dissertations and Theses.

[23] Bowdoin, C. (2014) Thinking Like a Nurse and Perceived Readiness for Professional Practice: A Mixed Methods Study. Mercer University, Macon.

[24] Saaranen, T., Vaajoki, A., Kellomäki, M. and Hyvärinen, M.-L. (2015) The Simulation Method in Learning Interpersonal Communication Competence-Experiences of Masters' Degree students of Health Sciences. Nurse Education Today, 35, e8-e13. https://doi.org/10.1016/j.nedt.2014.12.012

[25] Allan, H.T., Smith, P. and O'Driscoll, M. (2011) Experiences of Supernumerary Status and the Hidden Curriculum in Nursing: A New Twist in the Theory-Practice 
gap? Journal of Clinical Nursing, 20, 847-855.

https://doi.org/10.1111/j.1365-2702.2010.03570.x

[26] Morrell, N. and Ridgway, V. (2014) Are We Preparing Student Nurses for Final Practice Placement? British Journal of Nursing, 23, 518-523.

https://doi.org/10.12968/bjon.2014.23.10.518

[27] Brown, H.D. (2016) Examination of baccalaureate Nursing Students' Readiness for Practice. Colorado State University-Pueblo, Pueblo.

[28] Fitzgerald, M. (2019) The Perception of Student Nurses' Progress towards Practice Readiness in a Revised Baccalaureate Nursing Program. Doctoral Thesis, Northeastern University, Boston Massachusetts.

[29] Watt, E. and Pascoe, E. (2013) An Exploration of Graduate Nurses' Perceptions of Their Preparedness for Practice after Undertaking the Final Year of Their Bachelor of Nursing Degree in a University-Based Clinical School of Nursing. International Journal of Nursing Practice, 19, 23-30. https://doi.org/10.1111/ijn.12032

[30] Hickey, M.T. (2009) Preceptor Perceptions of New Graduate Nurse Readiness for Practice. Journal for Nurses in Professional Development, 25, 35-41.

https://doi.org/10.1097/NND.0b013e318194b5bb

[31] Lasater, K. and Nielsen, A. (2009) Reflective Journaling for Clinical Judgment Development and Evaluation. Journal of Nursing Education, 48, 40-44. https://doi.org/10.3928/01484834-20090101-06

[32] Schuessler, J.B., Wilder, B. and Byrd, L.W. (2012) Reflective Journaling and Development of Cultural Humility in Students. Nursing Education Perspectives, 33, 96-99. https://doi.org/10.5480/1536-5026-33.2.96

[33] Simpson, E. and Courtney, M. (2007) A Framework Guiding Critical Thinking through Reflective Journal Documentation: A Middle Eastern Experience. International Journal of Nursing Practice, 13, 203-208.

https://doi.org/10.1111/j.1440-172X.2007.00629.x

[34] Kangasniemi, M., Pakkanen, P. and Korhonen, A. (2015) Professional Ethics in Nursing: An Integrative Review. Journal of Advanced Nursing, 71, 1744-1757. https://doi.org/10.1111/jan.12619

[35] Levett-Jones, T., Gersbach, J., Arthur, C. and Roche, J. (2011) Implementing a Clinical Competency Assessment Model That Promotes Critical Reflection and Ensures nursing Graduates' Readiness for Professional Practice. Nurse Education in Practice, 11, 64-69. https://doi.org/10.1016/j.nepr.2010.07.004

[36] Glass, B.W. and Wallace, B.C. (2012) Staff-Designed Labor and Delivery Practice Improvement. Journal of Obstetric, Gynecologic \& Neonatal Nursing, 41, S70-S71. https://doi.org/10.1111/j.1552-6909.2012.01361_22.x

[37] Gaberson, K. and Oermann, M. (2010) Clinical Teaching Strategies in Nursing. Springer Publishing Company, New York.

[38] Dlamini, C.P., Mtshali, N.G., Dlamini, C.H., Mahanya, S., Shabangu, T. and Tsabedze, Z. (2014) New Graduates' Readiness for Practice in Swaziland: An Exploration of Stakeholders' Perspectives. Journal of Nursing Education and Practice, 4, 148-158. https://doi.org/10.5430/jnep.v4n5p148

[39] Sacred Heart University (2020) The Importance of Nursing Specializations 2020. 